RAE-IC, Revista de la Asociación Española de Investigación de la Comunicación vol. 8, núm. 15 (2021), 333-356 ISSN 2341-2690

Recibido el 1 de diciembre de 2020 DOI: https://doi.org/10.24137/raeic.8.15.15 Aceptado el 2 de enero de 2021

\title{
Horror vacui como principio interpretativo del fenómeno contemporáneo de saturación con música de fondo
}

Horror Vacui as an Heuristic Principle of the Contemporary Phenomenon of Saturation with Background Music

Guirao Piñera, Antonio

Universidad de Murcia (UM)

aguirao@um.es

Forma de citar este artículo:

Guirao Piñera, A. (2021). Horror vacui como principio interpretativo del fenómeno contemporáneo de saturación con música de fondo. RAE-IC, Revista de la Asociación Española de Investigación de la Comunicación, 8(15), 333-356. https://doi.org/10.24137/raeic.8.15.15

\section{Resumen:}

La música se ha generalizado en todos los contextos, incluidos el comercial, social y laboral, y el sonido ha invadido el espacio público. La música posee una enorme capacidad comunicativa y gran efectividad para generar emociones. Así, se ha empleado en publicidad como herramienta de atracción y como fórmula para producir respuestas positivas en los individuos. Sin embargo, su presencia excesiva indica una tendencia o necesidad a rellenar todo el espacio con sonidos, sin cabida para el silencio. En este trabajo presentamos este fenómeno como una manifestación en la sociedad actual del "horror vacui", expresión latina que significa "miedo al espacio vacío", cuyo origen se 
encuentra en el paradigma filosófico que negaba el vacío en la naturaleza y pasó después a aplicarse en historia del arte para describir las obras repletas y ornamentadas, sin huecos, como las del Barroco. Proponemos este paralelismo como método de investigación en comunicación musical.

Palabras clave: Horror vacui, música, silencio, saturación, vacío, continuo.

\section{Abstract:}

We are experiencing a generalization of music in all contexts, including the commercial, social and labour, to the point that sound has invaded the public space. Music has a great communication power and effectiveness in generating emotions and attitudes. Thus, music has been used as a persuasion tool in advertising and as a formula to produce positive responses in individuals. However, its excessive presence suggests a current tendency or need to fill the entire space with sounds, with no room for silence. In this work, we present this phenomenon as a manifestation in modern societies of the "horror vacui", a Latin expression that means "fear of empty space", whose origin is in the philosophical paradigm that denied the emptiness in nature and was later applied in art history to describe ornate works, without gaps, like those of the Baroque. We propose this parallelism as a research method in musical communication.

Keywords: Horror vacui, music, silence, saturation, void, continuous.

\section{INTRODUCCIÓN}

La música es ubicua hoy día. Desde el siglo XX hasta ahora su uso ha crecido exponencialmente hasta invadir el espacio público. Estamos expuestos a un casi continuo fondo musical a través de distintos formatos y situaciones (anuncios publicitarios, centros comerciales, espacios de espera, tiendas, etc.).

La música es un importante canal de comunicación y tiene una gran capacidad emocional. Ello ha llevado a aprovecharla estratégicamente para producir respuestas en los individuos. Así, la música es inseparable de la publicidad, donde se utiliza para influir 
en las preferencias del consumidor. En los centros comerciales se emplea para modular el comportamiento de los clientes y orientarlos hacia determinados productos, o como simple telón de fondo. Y el hilo musical se ha extendido con la intención de conseguir respuestas positivas en multitud de espacios públicos y entornos laborales.

Pero más allá del uso intencional (emotivo o mercadotécnico) de la música, se ha llegado a una situación de evasión del silencio; todo se rellena musicalmente, sin intervalos vacíos. En este trabajo presentamos este fenómeno como manifestación en la sociedad actual del "horror vacui", expresión latina que significa "miedo al espacio vacío" con origen en el paradigma filosófico que negaba el vacío en la naturaleza, aplicada después en arte para describir el relleno de todo el espacio en una obra. Realizamos primero una extensa revisión del concepto en historia de la ciencia y en historia del arte; después examinamos la expansión del uso de la música; y finalmente relacionamos los tres ámbitos discutiendo el fenómeno como un horror vacui musical.

\section{PRINCIPIO NATURAL DEL RECHAZO AL VACÍO}

El término "horror vacui" procede de la filosofía natural, donde está relacionado con la negación del vacío en la naturaleza. La idea se remonta a los presocráticos. Para Anaxágoras el vacío no existe porque supondría un espacio absolutamente incorpóreo, contradicho por la evidencia empírica: en una botella sumergida boca abajo el aire interior impide entrar al agua, así que la oquedad no es vacío sino aire (Megino, 2002, p. 320). El precursor más representativo del horror vacui es Aristóteles. Dijo en su Física: “Que no hay vacío separado, tal como algunos afirman, digámoslo de nuevo" (Aristóteles, 1995, p. 138). Como el vacío no es causa de ningún efecto en la naturaleza, no se puede postular (von Guericke, 1962, p. 55). Y, en contra de los defensores del vacío, Aristóteles afirmó que "incluso si se lo considera en sí mismo parece que el llamado vacío es verdaderamente vacío" (Aristóteles, 1995, p. 142), lo que Thorp (1990) considera una broma deliberada para rechazar el concepto sin chance para una contraargumentación.

No todos los pensadores griegos negaron el vacío. Los pitagóricos y los atomistas Leucipo y Demócrito postularon su realidad y lo convirtieron en pieza clave de la cosmología (Megino, 2002). Para los atomistas todo el universo está compuesto de 
átomos, partículas materiales indivisibles y minúsculas, que se mueven, colisionan, se reúnen... Y eso ha de ocurrir en el vacío. Los atomistas certifican al vacío como la condición de posibilidad de todo movimiento o cambio. Por su parte, Herón de Alejandría opina en su Neumática que existe un vacío natural fraccionado en los intersticios de las partículas (por compresión entra más aire en un recipiente rígido), y un vacío continuo que aparecería sólo como resultado de una fuerza, como la de succión que permite dejar suspendida en los labios una vasija angosta (Herón, 2016, pp. 9-17).

El concepto de vacío ocupa un lugar central en la Edad Media. Es entonces cuando se establece la máxima de que "la naturaleza aborrece al vacío". Por un lado, el vacío fue objeto de las discusiones escolásticas, con Guillermo de Ockham cuestionando si "el vacío es nada, o la nada es un vacío", Jean Buridan reflexionando sobre si el vacío se aplica al volumen sin nada o a la superficie que lo encierra, o Roger Bacon concibiendo un vacío extracósmico (Grant, 1981, pp. 12-13). Por otro lado, el estudio de fenómenos relacionados con el movimiento del aire y el agua traerá una novedad. Aristóteles, en De Caelo, expuso que el agua no puede subir para ocupar el lugar del aire. Y Filón de Bizancio consideró que aire y agua eran sustancias continuas y unidas, al observar que un líquido asciende por un tubo siguiendo al aire aspirado por el otro extremo. La interpretación a estos hechos en la Edad Media (por ejemplo, por Averroes) se hizo apelando a una oposición o resistencia de la naturaleza al vacío; dicho de otro modo, la naturaleza actúa en orden a evitar o prevenir la formación de un vacío; así, si un volumen se desplaza, otro volumen ocupará su lugar (Grant, 1981, pp. 67-100).

También era conocido que las paredes de un fuelle comprimido quedan pegadas y no pueden separarse si tapamos el orificio de entrada y salida de aire. Y en una clepsidra (una vasija alargada y estrecha, con la base ancha y perforada, utilizada para catar vinos), el vino que ha entrado por los agujeros inferiores no escapa cuando se tapona la boca superior de la vasija. Para los medievales, la causa de estos fenómenos era la prevención del vacío por parte de la propia naturaleza. Así, durante el siglo XIII aparecen las expresiones latinas que enuncian la idea: "natura abhorret vacuum", "horror vacui" y "fuga vacui". El horror vacui se elevó al rango de principio universal. Roger Bacon y Walter Burley hablaron de un agente universal que tiende a preservar la continuidad 
material y es signo de la perfección de la naturaleza (Grant, 1981, pp. 84-85). A propósito del término "vacío", el Diccionario de Inglés de Oxford cita a Thomas Cranmer, arzobispo de Canterbury, que enunció la frase "la razón natural aborrece el vacío" como parte de un argumento teológico (Williams, 2012).

Curiosamente, en contra de lo anterior, este principio natural de imposibilidad del vacío se vio desde el ámbito teológico como una de las limitaciones a la omnipotencia divina que derivaron en varios pronunciamientos contra las tesis del aristotelismo heterodoxo o averroísmo. Entre ellos, fue paradigmático el Syllabus de 1277 del obispo de París, Étienne Tempier, con una lista de 219 "errores execrables", algunos de ellos de la filosofía natural. En concreto, la proposición 49 reflejaba el error de que Dios, si así fuese su voluntad, no pudiera producir movimientos que dejaran un vacío (Glick et al., 2014, pp. 142-143; Prieto, 2020).

El paradigma aristotélico dominó hasta el siglo XVII. Como en los físicos estoicos, la piedra angular del mundo de Descartes fue un cosmos continuo, donde extensión significaba materia. Para los estoicos el "pneuma" era una sustancia primordial que permea todo el universo (Sambursky, 1956, pp. 132-135). Para Descartes todas las partículas materiales están pegadas y constantemente arremolinándose a modo de vórtices para impedir un vacío (Descartes, 2004, pp. 32-41). El mismo Galileo adoptó el principio de horror vacui, aunque admitió un vacío momentáneo tras separar rápidamente dos superficies en contacto: “... el vacío a veces se produce por un movimiento violento o contrario a las leyes de la naturaleza" (Galilei, 1914, pp. 31-32).

La construcción de la bomba de vacío por Otto von Guericke inició una nueva era (Kleint, 1998). Guericke realizó el espectacular experimento de los hemisferios de Magdeburgo, que ocho caballos a cada lado no pudieron abrir, falsando así la hipótesis de Buridan cuando afirmó (Grant, 1981, p. 82) que "ni veinte caballos con diez tirando de cada lado podrían vencer esta tendencia natural". En la misma época, Evangelista Torricelli inventó otro instrumento clave, el barómetro. Al descender por gravedad la columna de mercurio dentro del tubo, cerrado por arriba, deja un hueco en la parte superior "lleno de nada". De esta manera, el horror vacui se convirtió también en una de las discusiones 
importantes de la revolución científica del XVII. Blaise Pascal se resistió a renunciar al paradigma medieval, pero comprobó que en la cima de la montaña Puy-de-Dôme el nivel del mercurio era inferior y dejaba más espacio vacío dentro del tubo. Pascal consideró este resultado una prueba irrefutable: "el [experimento] practicado en las montañas ha puesto fin a la creencia universal en el horror de la naturaleza al vacío, abriendo el camino a la idea -ya incuestionable- de que la naturaleza no experimenta horror alguno al vacío, que no hace nada por evitarlo".

Sin embargo, los físicos siguieron pensando el cosmos como un plenum. En los siglos XVIII y XIX, la electricidad y el calor se trataron como fluidos continuos. Y la aversión a que la luz y las ondas electromagnéticas pudieran viajar en el vacío, hizo postular el éter cartesiano como sustancia sutil que todo lo llena. Sólo el experimento de MichelsonMorley y la teoría de la relatividad de Einstein permitieron desterrar la necesidad de un soporte material para la propagación de la luz.

Una especial relación con el vacío es la que tienen las ondas sonoras, que no pueden existir sin un medio material. Un universo relleno implicaría que el sonido puede transmitirse en todo lugar. Así, Johannes Kepler fundó la "música celeste" al pensar que los planetas emitían tonos musicales mientras giran en torno al Sol. La física moderna dicta que eso no es posible y, por tanto, en el vacío se da un "silencio" físico. Sin embargo, otra cosa es la sensación de silencio como percepción psicoacústica. En este sentido, la ausencia total de sonido no existe, pues el ser humano siempre percibe sonidos ya sean de tipo externo o interno (Schmidgen, 2013; Torras, 2014).

\section{HORROR VACUI EN LA HISTORIA DEL ARTE}

\subsection{EJEMPLOS DE UN ARTE QUE REBOSA}

El miedo al espacio vacío está íntimamente relacionado con la historia del arte. "Horror vacui" se utiliza para describir las obras repletas, abarrotadas de elementos que cubren toda la superficie. Este estilo es característico de la estética del Barroco, de la decoración islámica y del arte bizantino, pero su uso se extiende en multitud de formatos a lo largo de la historia. Un ejemplo paradigmático es el Sarcófago Ludovisi, en el Palacio Altemps del Museo 
Nacional Romano, un sarcófago de mármol del siglo III totalmente esculpido con una masa confusa de combatientes bárbaros y romanos entremezclados. Las piezas de cerámica ibérica están pintadas con complejas escenas que rellenan al máximo el espacio. Los artistas árabes también parecen estar obsesionados con el horror vacui, y dejan esa impronta en alfombras, losetas y decoración (Ettinghausen, 1979). Otro ejemplo son los arabescos, como los del Mihrab de la Mezquita de Córdoba o los de la Alhambra de Granada. Y rebosa de detalles el grabado La caída de Babilonia de Jean Duvet.

El horror vacui suele asociarse especialmente con el Barroco por su estilo ornamental y recargado. En la arquitectura barroca se rompe la geometría lineal añadiendo curvaturas y ondulaciones (por ejemplo, el baldaquino de la Basílica de San Pedro o la fachada de la catedral de Murcia). En la pintura se tiende a rellenar todos los espacios sin dejar apenas huecos en la composición (Adoración de los Reyes Magos de Rubens, La ronda de noche de Rembrandt). En la literatura se puede relacionar el horror vacui con el culteranismo de abundantes metáforas y cultismos (La vida es sueño de Calderón de la Barca, Fábula de Píramo y Tisbe de Góngora). El horror vacui en el barroco musical se aprecia en el uso del basso continuo con el sonido del bajo continuamente presente (sonata BWV1039 de Bach, sonata K90 de Scarlatti).

\subsection{USO DEL TÉRMINO}

En la mayoría de textos se atribuye a Mario Praz, un crítico de arte y literatura italiano, el uso del término para criticar el fetiche victoriano de saturar los diseños. Sin embargo, la idea fue utilizada antes por el alemán Johann Joachim Winckelmann. En su crítica al arte rococó, el influyente historiador escribe: "Las pinturas en los techos, puertas y chimeneas sólo están allí para llenar el espacio vacío y cubrir los huecos que el simple dorado no llenó. No tienen ninguna relación con el rango y las circunstancias del propietario, incluso son una desventaja. El disgusto por el espacio vacío llena las paredes, y las pinturas, vacías de pensamiento, reemplazan al vacío" (Winckelmann, 1765, p. 62). Winckelmann confronta el "horror vacui" con el buen gusto y la razón del arte griego, donde encuentra su ideal. Como los griegos, rechaza el ornamento en favor 
de la simplicidad: "La última y más eminente característica de las obras griegas es una noble sencillez y una silenciosa grandeza" (Winckelmann, 1765, p. 30).

Un siglo después, el arquitecto y diseñador inglés Augustus Pugin considera un error el uso excesivo de piezas decoradas en la arquitectura gótica. Pugin identifica la belleza con la adecuación del proyecto a su fin, es decir, condiciona el diseño y la decoración a la funcionalidad y utilidad. En arquitectura hasta el menor detalle debe servir a un propósito; dice Pugin: "La Capilla de Enrique VII en Westminster se considera justamente uno de los más maravillosos ejemplos de la construcción ingeniosa... pero al mismo tiempo exhibe el inicio del mal gusto, por construir el ornamento en lugar de limitarlo al enriquecimiento de la propia construcción. Me refiero a los colgantes de piedra del techo, que son sin duda extravagancias" (citado en Dávila, 2014).

Walter Benjamin señala el impulso a coleccionar y hacer acopio de todo tipo de objetos para llenar los espacios interiores y poder "habitarlos".

Mario Praz utilizó el horror vacui como crítica al estilo de los interiores burgueses, los cuáles eran desordenados y agobiantes. En el estilo victoriano del siglo XIX "el horror vacui era algo habitual" (Praz, 1964a, p. 94), y la decoración de las habitaciones transmitía "sensación de horror vacui" (Praz, 1964b, p. 375). La saturación del diseño de interiores comenzaba a ser abrumador $y$, contraproducentemente, a reducir el atractivo de los espacios habitables (Soegaard, 2020). En el hogar burgués el horror vacui dictaba el sentido último de la decoración: "tapices, cuadros, alfombras, rinconeras, floreros, cortinajes, jarrones, figuras de porcelana, en profusa mescolanza, llenan inmisericordes cualquier hueco o rincón que se ofrezca libre de todo uso y ocupación." (Castillo, 1995). Más recientemente, horror vacui se ha utilizado en el ámbito del diseño para referirse a la sobrecarga en anuncios, escaparates y periódicos (Lidwell et al., 2010, p. 197).

\section{MÚSICA DE FONDO}

\subsection{MÚSICA, COMUNICACIÓN Y EMOCIONES}


La música es un importantísimo canal de comunicación. Con ella compartimos emociones, intenciones y significados. $Y$ tiene la capacidad de generar efectos en el cuerpo y el comportamiento. Además, puede transmitir una infinita diversidad de matices, lo que permite una comunicación de información muy efectiva (Hargreaves et al., 2005, p. 1). La experiencia musical consigue que los individuos sean más positivos y se sientan mejor, según recogen Sloboda y O'Neill (2001) de su revisión de la literatura. De hecho, uno de los retos en la investigación musical es entender cómo respondemos a la música (Juslin y Laukka, 2004).

La ciencia ha ido prestando cada vez más atención al papel de la música y las emociones. Inicialmente, se abordó el fenómeno musical mediante la teoría de la información de Shannon y Weaver (1949), aunque ésta resultó limitada por su unidireccionalidad. El paradigma de la psicología entró entonces a estudiar los mecanismos de procesamiento de información musical. En la obra de referencia Emoción y significado en la música, Leonard Meyer se acerca desde la psicología al hecho musical mediante la síntesis de la teoría de la Gestalt y la teoría de la información, destacando la importancia de elementos como la incertidumbre y la naturaleza probabilística (Turina, 2001; Eco, 1970, pp. 168-186). Además, al explicar el significado musical como la "experiencia" que surge de la relación triádica entre oyente, estímulo y expectaciones que éste genera, Meyer se sitúa en un espacio intermedio entre dos corrientes tradicionalmente opuestas: la formalista (o "música absoluta") que fija el significado musical en la obra misma, y la referencialista (o programática) que apunta a sensaciones y emociones extra-musicales inducidas en el oyente (Meyer, 1961, pp. 1-42). Recientemente, el comportamiento musical se ha abordado en contextos amplios de la vida cotidiana con el individuo en relación con su entorno (Hargreaves et al., 2005, p. 5) y resaltando el contexto social en la aparición de las emociones (Juslin y Laukka, 2004).

\subsection{USO INTENCIONAL DE LA MÚSICA}

La capacidad de la música para generar actitudes y emociones se ha aprovechado en múltiples ámbitos como la educación y la salud, como medio de socialización o ideológico, y como herramienta de diseño de atmósferas y de marketing. La música se 
utiliza como terapia para resolver problemas emocionales y mejorar el rendimiento y la atención (Thaut y Wheeler, 2010, pp. 581-594). Se emplea para conseguir efectos beneficiosos en el ámbito laboral, en la medida en que la exposición a la música evoque estados de ánimo agradables y dinámicos (Lesiuk, 2005; Wilson, 2018). Así, las empresas pueden emplear hilo musical con la intención de optimizar el rendimiento de sus empleados. En el ámbito social, la música (por ejemplo, a través de los himnos) puede promover el patriotismo. También se canaliza hacia objetivos solidarios (recuérdese, por ejemplo, la canción We are the world), de cooperación y de interconexión social (Garofalo, 2010, pp. 522-523).

El poder de la música ambiente no es un descubrimiento reciente (North y Hargreaves, 2005, p. 408). La mitología griega cuenta que Orfeo tocó su lira para inspirar a Jason y a los Argonautas en la búsqueda del vellocino de oro. Para el gramático romano Censorino la música hace el trabajo más soportable, como cuando el timonel la utiliza en una galera. $Y$ durante la Edad Media, en las primeras Cruzadas los cristianos se acompañaron en el campo de batalla de la misma música militar que ayudó a los sarracenos en batallas anteriores.

En el terreno de la publicidad, la música ejerce como agente potenciador de la comunicación y del recuerdo del mensaje. También sirve para segmentar, fidelizar y crear imagen de marca (North y Hargreaves, 2005, p. 647). Una tienda de ropa para jóvenes suele tener música electrónica a volumen alto, mientras que en una tienda de muebles de lujo podemos escuchar a Mozart de fondo. Este uso intencional de la música por sus efectos en el consumo está relacionado con el condicionamiento clásico de Paulov (Schachtman et al., 2011, pp. 481-506). Existe evidencia empírica sobre la posibilidad de generar emociones y actitudes positivas asociadas con un producto, o con los puntos de venta, utilizando estímulos incondicionados (como colores atractivos y música agradable). Algunos estudios conductuales muestran que la asociación entre un producto y un estímulo musical influye en las preferencias del consumidor (Gorn, 1982). Y se ha demostrado que, a mayor rapidez de la música, más deprisa actúan los clientes (North y Hargreaves, 2005, p. 408). Así, se puede utilizar la música de forma dirigida para redistribuir clientes entre zonas más o menos congestionadas, o para mantener a los clientes observando un producto bajo la hipótesis de que ello aumenta la probabilidad 
de comprarlo. Los vendedores crean el ambiente in-store para aumentar las ventas vía conexión cognitiva de los clientes. La música se pretende "adecuar" a productos específicos para maximizar el resultado cognitivo (Hargreaves et al., 2005, p. 10).

\subsection{MUZAK: DEL ELEVATOR MUSIC A LA RADIO IN STORE}

El origen de la música de fondo o música ambiente es el muzak, una tecnología de transmisión de música por cable (hilo musical) en lugar de por ondas hertzianas. La inventó el militar George Squier durante la Primera Guerra Mundial y la llamó “muzak” combinando estratégicamente las palabras “música” y la conocida “Kodak" (Jackson, 2003, p. 13). Squier fundó la compañía Muzak, que proporcionaba el servicio técnico y también las sesiones musicales, de estilo calmado. Es la música que asociamos a los ascensores, donde se pretende llenar el ambiente y relajar, conocida popularmente como elevator music (Lanza, 2004). El muzak tuvo tanto éxito que empezó a utilizarse de forma habitual en hoteles, restaurantes y clubs. Su influencia fue extraordinaria e inspiró un nuevo género, la música ambiental, que se extendió a múltiples ámbitos: consultas médicas, aeropuertos, peluquerías, centros comerciales... El muzak no se limitó a una herramienta orientada al consumidor y pasó también al contexto laboral para influir positivamente en el estado de ánimo de los trabajadores y aumentar su rendimiento. Incluso la Nasa ha utilizado esta música para evitar el estrés de los astronautas. En España, el equivalente fue el hilo musical desarrollado por la Compañía Telefónica Nacional en 1969, que ofrecía música a hogares, tiendas, hoteles, etc. sin interferencias ni anuncios.

El uso cada vez más extendido de la música ambiental ha conducido a la aparición de las radios corporativas, estaciones de radio online diseñadas a medida por empresas específicas con la colaboración de grupos de comunicación (Prata y Martins, 2017; PiñeiroOtero, 2015). Por ejemplo, la staff radio es un canal de comunicación interna en una empresa pensado como elemento de motivación organizacional y fomento de las buenas relaciones interpersonales (como la radio de Apple). Las radios institucionales son emisoras diseñadas para organismos públicos y entidades políticas, sociales o culturales. La brand radio ofrece contenidos musicales e informativos asociados a los valores de marca (como el audio a bordo de Renfe). Finalmente, la in-store radio es el formato heredero del hilo 
musical convencional y se utiliza en los centros comerciales y en los espacios de trabajo para crear un ambiente sonoro que conecte con los clientes y contribuya positivamente en los empleados (Piñeiro-Otero, 2015; Peinado-Miguel et al., 2017).

\subsection{MÚSICA PUBLICITARIA}

La evolución de la publicidad va ligada a la música. La música contribuye a la eficacia de la publicidad porque la hace más atractiva, le aporta sentido, crea un recuerdo en el consumidor y ayuda a que el mensaje penetre de una manera subliminal (PalenciaLefler, 2009). El anunciante busca con la música atraer la atención del espectador, despertar su interés e impulsarle a la acción. Cabe destacar la fuerza de los primeros jingles radiofónicos y de televisión (como el exitoso l'd like to buy the world a coke de Coca-Cola, o el de Nocilla). El jingle es un tema musical corto cuyo poder comunicativo reside en la conjunción música-letra. Suele ser alegre, pegadizo y fácilmente recordable. Hace alusión a los atributos del producto o a algún vínculo emocional con el consumidor (Jackson, 2003, pp. 9-15).

Los jingles dieron paso al uso de música y canciones de fondo que acompañan casi de forma ininterrumpida al mensaje verbal o visual de los anuncios. Las canciones para los anuncios comerciales, aunque en ocasiones son originales, suelen ser canciones conocidas de algún artista utilizadas de forma íntegra, adaptada o como cover. Por ejemplo, la canción de Phil Collins In the air tonight se utilizó para el anuncio de chocolates Cadbury, premiado en el Festival de Publicidad de Cannes. En las canciones adaptadas y en las versiones se juega a la vez con el reconocimiento de la melodía y con la adecuación a las necesidades del mensaje publicitario.

Más allá de la música publicitaria, el brand sound está al servicio de la identidad corporativa. Son sonidos breves diseñados de forma estratégica que facilitan el recuerdo de una marca y la revalorizan. Dentro de ellos se distinguen (Piñeiro-Otero, 2015): el logo sonoro, o símbolo sonoro de la marca (como el arranque de Windows 95 creado por Brian Eno); el claim sonoro, que elogia las cualidades del producto (I'm loving it de McDonald's); la canción de marca (melodía del teléfono Nokia basada en el Grand Vals 
de Tárrega); la voz de marca; el diseño sonoro del producto (clic de la cámara del iPhone); y el paisaje sonoro, para fondos en vídeos, internet, etc.

\section{HORROR AL SILENCIO}

\subsection{LA UBICUIDAD DE LA MÚSICA}

La música es ubicua en nuestra sociedad contemporánea. Si en el pasado la audición se limitaba a los conciertos en directo o, más tarde, cuando surgieron los medios de grabación-reproducción, a la práctica voluntaria y privada (como reproducir un vinilo en el tocadiscos de casa o sintonizar una emisora de radio musical), hoy día podemos escuchar música en multitud de situaciones. Podríamos decir que se ha producido una universalización de los auditorios. Especialmente remarcable es la configuración de la "sono-esfera digital" (Perona-Páez et al., 2014) que permite al individuo personalizar su universo sonoro mediante los dispositivos electrónicos-digitales, una alternativa a la radio tradicional, principal encargada en la era analógica de rellenar el espacio musical.

Incluso fuera de nuestra elección, escuchamos música en los anuncios, centralitas telefónicas, ascensores, centros comerciales, aeropuertos, cafeterías, tiendas, salas de espera, parkings... Estamos expuestos a música una buena parte de nuestro tiempo; la música se ha convertido en un sound track to life (Hargreaves et al., 2005, p. 10). Tan omnipresente es la música que la ciencia presta cada vez más atención a este fenómeno. Así, el tópico "música en la vida cotidiana" (music in everyday life) es ahora común en la literatura científica (MacDonald, 2016, pp. 719-789; Sloboda, 2010, p. 355).

\subsection{HORROR VACUI MUSICAL}

La saturación musical en el espacio público parece no ser únicamente el producto de una estrategia, diseñada en el sentido discutido anteriormente. Más allá de la intención emotiva o mercadotécnica, el recurso constante a la música apunta a una tendencia, ya sea intrínseca o cultural, a evitar el silencio. Así, esta ubicuidad de la música podría explicarse en parte como un fenómeno renovado de horror vacui. Posiblemente, una de las primeras manifestaciones de esta tendencia al relleno sonoro se dio en los inicios del cine cuando, como señala Altman (2004), era habitual la presencia de pianistas y 
orquestas acompañando musicalmente las películas de cine mudo. El concepto de miedo al espacio vacío que otrora se manifestó en el arte o en la conceptualización de la naturaleza, ahora surge como compulsión a completar con sonido.

El relleno musical da continuidad a los anuncios publicitarios. Al igual que el basso continuo de la música barroca, ahora suena la música sin cesar acompañando al mensaje oral y verbal. El hilo musical de los espacios comerciales permite evitar la sensación de soledad. Quizás ocurre como en las abarrotadas ciudades árabes, donde el vacío (Ettinghausen, 1979, p. 19) es lo antagónico a la civilización y, por tanto, al bienestar, pues más allá de los muros está el desierto. Los interiores burgueses que criticara Praz, quizás en cierto modo, causan una agradable claustrofobia, como la que podemos experimentar en los interiores de los centros comerciales donde es la música de fondo la que recarga el ambiente. En el hogar moderno, con su "capacidad casi ilimitada para acoger electrodomésticos, artilugios y cachivaches" (Castillo, 1995), también podemos encontrar esa seguridad según buscamos el ruido y el bullicio de las ciudades al que estamos acostumbrados (Domínguez, 2014).

El horror vacui es un fenómeno psicológico, social y cultural. Para la psicología el principio es la manifestación de un instinto natural, el instinto humano de decorar, de completar los huecos. Ese mismo instinto extendido a la interpretación de la naturaleza puede llevarnos a intentar percibirla como un plenum, a rechazar el vacío. Aunque quizás es una cuestión más transcendental. Como sostiene Benjamin, el hombre del Barroco se aferra a su mundo pletórico de cosas porque más allá ve el vacío. En los excesos decorativos del barroco hay un sentimiento de pérdida y anhelo de lo absoluto, y una intención de alcanzar lo supremo (Castillo, 2005, p. 87). Y Heidegger señala la angustia que nos despierta la nada. También se ha discutido el miedo al vacío sociológico generado por la falta de ingredientes sociales (Pawlak, 2015). La filosofía natural aristotélica proporciona una sensación de seguridad, es una zona de confort libre de sorpresas (Blum, 2017). Con esa misma lógica, el horror vacui musical nos arroparía en un mundo "seguro".

\subsection{CRÍTICAS A LA MÚSICA DE FONDO}


Ante la omnipresencia de la música ambiente, y en contraposición con sus aspectos positivos, una parte de la ciudadanía la considera música enlatada que invade nuestra libertad personal e induce estados de ánimo de satisfacción pasiva. El rechazo a la música en espacios públicos ha dado lugar a distintas campañas y asociaciones. Por ejemplo, Pipedown (1992) lucha "por la libertad ante la música de fondo no deseada" argumentando que esta música puede afectar a la salud y que hay más gente a quien le disgusta que la contraria; y pretende que se retire la música, por ejemplo, de aeropuertos y hospitales. Y la Right to Quiet Society for Soundscape Awareness and Protection (Quiet, 1982) defiende la tranquilidad como un derecho humano básico, destaca los beneficios del silencio y trabaja por la reducción del ruido.

Desde la ciencia también surgen posturas escépticas que, como mínimo, relativizan la afirmación de que la música ambiente es beneficiosa. Algunos estudios muestran que la música en espacios públicos genera una carga emocional que se puede manifestar en respuestas negativas como abandonar un comercio porque disgusta su música o a discutir con los empleados para que apaguen el hilo musical (Sloboda y O'Neill, 2001, pp. 415429). También se ha encontrado una resistencia a la música en espacios públicos que aumenta con la edad y que la mayoría de personas mayores no concibe la música de fondo como "música" (DeNora, 1999). Se ha mostrado que la música puede ser una distracción en tareas que implican comprensión, atención y vigilancia (Dalton y Behm, 2007). Por otra parte, North y Hargreaves (2005, p. 648) advierten de que el supuesto efecto de la música se ha investigado sobre todo en condiciones de laboratorio, que existen estereotipos no demostrados en el music fit (por ejemplo, una guitarra eléctrica asociada a juventud), y que se requiere más estudios sobre si la música favorece o no al producto. En este sentido, el music fit es objeto de una importante línea de investigación en las últimas décadas que todavía no permite extraer conclusiones definitivas sobre el efecto de la música en las emociones y la conducta (Rentfrow et al., 2011; Zeeshan y Obaid, 2013).

\section{DISCUSIÓN}

El vacío tiene significado cultural y filosófico. Para los atomistas era la condición de posibilidad del movimiento. En el arte es un instrumento para crear diseños equilibrados 
y como "decoro" para que las cosas aparenten lo que son. Al igual que la naturaleza sí permite el vacío y que el minimalismo es posible en el arte, también queda espacio para el silencio. Algunos anuncios comerciales (como los de Apple) utilizan el silencio como sello de calidad y exclusividad. Pero por encima del "menos es más", el uso del silencio es una forma de comunicación efectiva (como el aire acondicionado del anuncio de Fujitsu; en el cine, Bergman hace protagonista al silencio como elemento narrativo y emotivo). El silencio es un elemento más de variación sonora, que genera contraste; también es ambigüedad comunicativa; y se emplea con intencionalidad en el producto audiovisual aportando su propio discurso (Torras, 2014). Cabe destacar, en relación con el arte, la interpretación del horror vacui que establece Heidegger de obras (como Zapatos de campesina de Van Gogh) que muestran zapatos vacíos que, en su vacío, hablan, atestiguan cosas (Godoy, 2017). En Occidente tendemos a llenar de sonido. En la cultura oriental el uso del vacío está relacionado con la espiritualidad y se busca el silencio "para encontrar" (van Eenoo, 2013). En este sentido, resulta interesante la propuesta del músico John Cage que en su 4'33" ofrece varios minutos de silencio. Antes, Cage había intentado experimentar el silencio total en la cámara anecoica de la Universidad de Harvard, comprobando que no es posible pues el cerebro percibe un continuo de sonidos internos del propio organismo.

La música por doquier termina por no escucharse e incluso por no oírse. Sólo si adoptamos la actitud adecuada llegamos a escuchar los sonidos. Así, Schaeffer (2017, p. 74) distingue cuatro modalidades de audición y señala que frente al mero "oír" (percepción auditiva y pasiva de los sonidos), "escuchar" es un proceso activo que exige prestar atención a lo que se oye. La música de fondo, si no despierta nuestro interés, no es escuchada. Además, al recibirse como sonido de fondo continuo, puede incluso dejar de oírse, de forma similar al fenómeno de "cansancio retiniano" en que dejamos de ver por adaptación a una señal visual constante. Por otro lado, la música como pasta de relleno crea una temporalidad de carácter continuo que pierde la solidez que le confieren los silencios. Usando la metáfora de lo "líquido" de Bauman, podríamos concebir el sonido como un fluido, al estilo de la física, que todo lo llena, y esa fluidez 
supondría la pérdida de anclaje al mundo. Además, según Adorno (2009), la música como producto de cambio pierde su carácter comunicativo.

El uso y abuso de la música puede conducir a que deje de importar su capacidad comunicativa, especialmente en el paradigma contemporáneo (Hormigos, 2010). Aunque se ha criticado que la música de fondo degrada la cultura (Bradshaw y Holbrook, 2008), lo cierto es que las marcas trabajan para atraer al público intentando aproximarse a sus intereses con contenidos musicales útiles y de calidad. Así, el branding musical es un fenómeno emergente donde se despliega una gran creatividad (Jackson, 2003). Lo que discutimos es el hecho en sí de la saturación musical, independientemente de que la música de fondo y publicitaria pueda ser negativa para ciertos consumidores (como señalan algunos estudios) y al margen de que dicha música esté o no adecuadamente diseñada o escogida (en muchos comercios simplemente suena un playlist con la música de moda). No existe necesidad real de rellenar el espacio con música, pero se tiende a ello por este horror vacui actual. En este sentido, se podría aplicar el adjetivo "barroco" en su sentido negativo original, como sinónimo de "absurdo" o "grotesco" ante el exceso de ornamentación. Si en literatura la profusión del vocabulario y su complicación formal permitían ejercitar la cultura y la inteligencia, el sonido constante de hoy, cuando no tiene justificación, sería pura retórica. Umberto Eco, sin embargo, pone en cierto valor a la música "sin valor" y, más allá del juicio estético, afirma que la canción de consumo "puede constituir un valor indispensable, que todas las sociedades sanas han perseguido y es el canal normal de desahogo para una serie de tensiones" (Eco, 1984, p. 321).

El horror vacui fue una técnica evitada por los modernistas como cambio de tendencia en el arte. Torricelli y Pascal desterraron la negación del vacío y el principio de su prohibición por la naturaleza. Estos dos cambios de paradigma nos sugieren otro similar respecto al miedo al silencio. Podríamos hacer una defensa del valor estético de lo vacío al estilo de la "pared desnuda" de Kandinsky, o proponer un dadaísmo contra el orden establecido al estilo Duchamp. 


\section{CONCLUSIONES}

El término horror vacui está asociado a un amplio marco conceptual que recorre la historia del pensamiento científico desde el mundo antiguo al moderno, aunque la expresión como tal surge en la Edad Media. Horror vacui representa el "miedo al vacío" y la concepción del cosmos como un plenum y un continuo, pero también la idea de que "la naturaleza aborrece al vacío", un principio universal de resistencia a la creación de vacío. La conceptualización en parejas de opuestos (Ileno/vacío) también permitió teorías defensoras del vacío como condición de posibilidad.

En el arte el horror vacui tiene que ver con una realidad variada de obras y diseños recargados, más habituales en el Barroco, con manifestaciones en casi todas las épocas. Aunque el uso del término en el arte suele asociarse a Praz, sin embargo, fue empleado previamente por Winckelmann y Pugin. El horror vacui tiene un sentido negativo, como crítica al excesivo ornamento. Por otro lado, apunta al instinto humano de llenar y decorar, y al ansia de seguridad y búsqueda de lo absoluto.

La música es ubicua hoy día. Se ha producido una progresiva inflación musical desde el siglo XX, ligada en parte al desarrollo de los medios de comunicación, la sociedad de consumo y la era digital. Desde la música ambiental a la publicitaria, el hecho conlleva la exposición a un casi continuo fondo musical que para muchos individuos resulta una invasión sonora del espacio público. La música es un canal importantísimo de comunicación, y tiene la capacidad de generar actitudes y emociones. Sin embargo, el uso excesivo o innecesario puede hacer que pierda su carácter comunicativo e incluso resultar desfavorable. La ciencia presta cada vez más atención a la comunicación musical, un área de investigación todavía joven que sigue aportando conocimiento sobre cómo respondemos a los estímulos musicales.

Creemos que existe hoy día una tendencia a evitar el silencio. Para interpretar este fenómeno de rellenar con música proponemos utilizar heurísticamente el principio del horror vacui que se manifestó en ciertos estilos artísticos y que fue atribuido a la naturaleza desde una postura filosófica de rechazo del vacío. Por otro lado, en la medida 
en que el vacío también tiene significado, subrayamos el valor del silencio como alternativa a la saturación musical.

\section{REFERENCIAS BIBLIOGRÁFICAS}

Adorno, T. W. (2009). Disonancias: introducción a la sociología de la música. Madrid: Akal.

Altman, R. (2004). Silent Film Sound. New York: Columbia University Press.

Aristóteles (1995). Física. Madrid: Gredos.

Blum, P. R. (2017). In fugam vacui - avoiding the void in Baroque thought. Quaestio, 17, 427-460. https://doi.org/10.1484/J.QUAESTIO.5.115300

Bradshaw, A. y Holbrook, M. B. (2008). Must we have Muzak wherever we go? A critical consideration of the consumer culture. Consumption, markets and culture, 11(1), 25-43. https://doi.org/10.1080/10253860701799959

Castillo, D. R. (2005). Horror (vacui): The Baroque condition. En N. Spadaccini, N. y L. Martín-Estudillo (Eds.), Hispanic Baroques: reading cultures in context. Nashville: Vanderbilt University Press.

Castillo, J. C. (1995). El hogar, un estilo de vida. Revista Internacional de Sociología, 12, 183.

Dalton, B. H. y Behm, D. (2007). Effects of noise and music on human and task performance: A systematic review. Occupational Ergonomics, 7(3), 143-152.

Dávila, D. (2014). Augustus Welby Northmore Pugin: ideología y teoría a través de sus textos. Cuaderno de Notas, 15, 155-167. https://doi.org/10.20868/cn.2014.2965

DeNora, T. (1999). Music as a technology of the self. Poetics, 27, 31-56.

Descartes, R. (2004). The world and other writings. Cambridge University Press. 
Domínguez, A. L. M. (2014). Vivir con ruido en la ciudad de México. El proceso de adaptación a los entornos acústicamente hostiles. Estudios demográficos y urbanos, 29(1), 89-112. http://dx.doi.org/10.24201/edu.v29i1.1456

Eco, U. (1970). La emoción musical: una explicación psicológica. En U. Eco, La definición de arte. Barcelona: Ed. Martínez Roca.

Eco, U. (1984). Apocalípticos e integrados. Lumen.

Ettinghausen, R. (1979). The taming of the horror vacui in Islamic art. Proceedings of the American Philosophical Society, 123(1), 15-28.

Galilei, G. (1914). Dialogues concerning two new sciences (H. Crew y A. de Salvio, trad.). New York: Macmillan. Recuperado de https://oll.libertyfund.org/title/galileidialogues-concerning-two-new-sciences

Garofalo, R. (2010). Politics, mediation, social context, and public use. En P. N. Juslin y J. A. Sloboda (Eds.), Music and emotion: Theory, research and applications. Oxford University Press.

Glick, T. F., Livesey, S. y Wallis, F. (Eds.) (2014). Medieval science, technology, and medicine: an encyclopedia. New York: Routledge.

https://doi.org/10.4324/9780203957868

Godoy, I. (2017). Horror vacui. Una aproximación al vacío de un par de zapatos a partir de Martin Heidegger. Ideas y Valores, 66(165), 111-132.

http://dx.doi.org/10.15446/ideasyvalores.v66n165.49010

Gorn, G. J. (1982). The effects of music in advertising on choice behavior: A classical conditioning approach. Journal of marketing , 46(1), 94-101.

https://doi.org/10.2307/1251163

Grant, E. (1981). Much ado about nothing: Theories of space and vacuum from the middle ages to the scientific revolution. Cambridge University Press. 
Hargreaves D. J., MacDonald y R., Miell, D. (2005). How do people communicate using music? En D. Miell, R. MacDonald y D. J. Hargreaves (Eds.), Musical communication. Oxford University Press.

Herón de Alejandría (2016). Neumática (B. Woodcroft, ed., London 1851; G. L. Mejía, trad.). Recuperado de http://www.librosmaravillosos.com/neumatica/

Hormigos, J. (2010). La creación de identidades culturales a través del sonido. Comunicar, 34, 91-98. https://doi.org/10.3916/C34-2010-02-09

Jackson, D. M. (2003). Sonic branding: an introduction. Basingstoke: Palgrave Macmillan.

Juslin, P. N. y Laukka, P. (2004). Expression, perception, and induction of musical emotions: A review and a questionnaire study of everyday listening. Journal of New Music Research, 33(3), 217-238. https://doi.org/10.1080/0929821042000317813

Kleint, C. (1998). Horror, happenings and highlights in the history of vacuum physics. Progress in surface science, 59, 301-312. https://doi.org/10.1016/S00796816(98)00056-2

Lanza, J. (2004). Elevator music: a surreal history of muzak, easy-listening, and other moodsong; revised and expanded edition. University of Michigan Press.

Lesiuk, T. (2005). The effect of music listening on work performance. Psychology of Music, 33, 173-191. https://doi.org/10.1177/0305735605050650

Lidwell, W., Holden, K. y Butler, J. (2010). Universal principles of design, revised and updated. Rockport Pub.

MacDonald, R. (2016). The role of music in our every days. En S. Hallam, I. Cross y M. Thaut (Eds.), Oxford handbook of music psychology. Oxford University Press. https://doi.org/10.1093/oxfordhb/9780198722946.001.0001

Megino, C. (2002). El origen de la idea de vacío en Grecia. Endoxa, 16, 313-332. https://doi.org/10.5944/endoxa.16.2002.5062 
Meyer, L. B. (1961). Emotion and meaning in music. University Chicago Press.

North, A. C. y Hargreaves, D. J. (2005). Musical communication in commercial contexts. En D. Miell, R. MacDonald y D. J. Hargreaves (Eds.), Musical communication. Oxford University Press.

Palencia-Lefler, M. (2009). Music in the advertising communication. Communication \& Society, 22(2), 89-108.

Pawlak, M. (2015). From sociological vacuum to horror vacui. Polish Sociological Review, 189(1), 5-27.

Peinado-Miguel, F., Rodríguez-Barba, D. y Rodríguez-Pallarés, M. (2017). Hacia un nuevo modelo de negocio radiofónico: la radio corporativa. Estudios sobre el mensaje periodístico, 23(1), 147. https://doi.org/10.5209/ESMP.55588

Perona-Páez, J. J., Barbeito-Veloso, M. y Fajula-Payet, A. (2014). Los jóvenes ante la sono-esfera digital: medios, dispositivos y hábitos de consumo sonoro. Comunicación y Sociedad, 27, 205-224. Recuperado de https://dadun.unav.edu/handle/10171/36271

Piñeiro-Otero, T. (2015). Del jingle a las radios corporativas: una aproximación al concepto de audiobranding. Prisma Social: revista de investigación social, 14, 663-668.

Pipedown (1992). The campaign for freedom from piped music. Recuperado de https://pipedown.org.uk/

Prata, N. y Martins, H. C. (2017). Brand radio: La segmentación personalizada como modelo de negocio. Revista de la Asociación Española de Investigación de la Comunicación, 4(7), 77-85. https://doi.org/10.24137/raeic.4.7.9

Praz, M. (1964a). The house of life. Oxford University Press.

Praz, M. (1964b). An illustrated history of furnishing from the Renaissance to the 20th century. New York: Ed. Braziller. 
Prieto, L. J. (2020). Reseña de Francisco León “1277, La condena de la filosofía. Edición del Syllabus del obispo Tempier en la Universidad de París". Éndoxa Series Filosóficas, 45, 287-294.

Quiet (1982). The Right to Quiet Society for Soundscape Awareness and Protection. Recuperado de http://www.quiet.org/

Rentfrow, P. J., Goldberg, L. R. y Levitin, D. J. (2011). The structure of musical preferences: a five-factor model. Journal of personality and social psychology, 100(6), 1139. https://doi.org/10.1037/a0022406

Sambursky, S. (1956). The physical world of the Greeks. Princeton University Press.

Schachtman, T. R., Walker, J. y Fowler, S. (2011). Effects of conditioning in advertising. En T. R. Schachtman y S. S. Reilly (Eds.), Associative learning and conditioning theory: Human and non-human applications. Oxford University Press.

Schmidgen, H. (2013). Camera silenta: time experiments, media networks, and the experience of organlessness. Osiris, 28(1), 162-188. https://doi.org/10.1086/671368

Schaeffer, P. (2017). Treatise on musical objects. University California Press.

Shannon, C. y Weaver, W. (1949). The mathematical theory of communication. University of Illinois Press.

Soegaard, M. (2020). Horror vacui: the fear of emptiness. The interaction design foundation. Recuperado de http://www.interactiondesign.org/literature/article/horror-vacui-the-fear-of-emptiness

Sloboda, J. A. y O'Neill, S. A. (2001). Emotions in everyday listening to music. En P. N. Juslin y J. A. Sloboda (Eds.), Music and emotion: Theory and research. Oxford University Press.

Sloboda, J. A. (2010). Music in everyday life: the role of emotions. En P. N. Juslin y J. A. Sloboda (Eds.), Music and emotion: Theory, research and applications. Oxford University Press. 
Thaut, M. H. y Wheeler, B. L. (2020). Music therapy. En P. N. Juslin y J. A. Sloboda (Eds.), Music and emotion: Theory, research and applications. Oxford University Press.

Thorp, J. (1990). Aristotle's horror vacui 1. Canadian Journal of Philosophy, 20(2), 149166. https://doi.org/10.1080/00455091.1990.10717213

Torras, D. (2014). La esencia del silencio audiovisual. 'El silencio' de Bergman como ejemplo. Revista Comunicación, 12, 82-93.

Turina, J. L. (2001). Introducción a la versión española de 'Emotion and Meaning in Music', de Leonard B. Meyer. Madrid: Alianza editorial.

van Eenoo, C. (2013). Empty space and silence. Arts and Design Studies, 15, 1-5.

von Guericke, O. (1962). Experimenta nova Magdeburgica de vacuo spatio (1672). Aalen: Ed. Otto Zeller.

Williams, R. (2012). October, 1644: Torricelli demonstrates the existence of a vacuum. American Physical Society News: This month in Physics History, 21(9). Recuperado de https://www.aps.org/publications/apsnews/201210/physicshistory.cfm

Wilson, C. (2018). The Impact of Music on Task Performance at Work [Undergraduate Thesis, University Arkansas]. ScholarWorks@UARK. Recuperado de https://scholarworks.uark.edu/acctuht/28

Winckelmann, J. J. (1765). Reflections on the painting and sculpture of the greeks (H. Fusseli, trad.). London: Millar. https://archive.org/details/reflectionsonpai00winc_0 Zeeshan, M. y Obaid, M. H. (2013). Impact of music on consumer behaviour: A perspective on retail atmospheric. Asian Journal of Business and Management Sciences, 3(2), 56-63. Recuperado de http://www.ajbms.org/articlepdf/5ajbms201303022769-06June14.pdf 